\title{
Физико-химическая трансформация гидропонного вермикулитового субстрата в процессе многолетней эксплуатации и проблемы экологии
}

\author{
Кременецкая И.П. ${ }^{1}$, Иванова Л.А. ${ }^{2}$, Числов М.В. ${ }^{3}$, Зверева И.А. ${ }^{3}$, Васильева Т.Н. ${ }^{1}$
}

${ }^{1}$ Институт химии и технологии редких элементов и минерального сырья им. И.В. Тананаева ФИЦ КНЦРАН», Anamumbl, i.kremenetskaia@ksc.ru

2 Полярно-альпийский ботанический сад-институт им. Н.А. Аврорина КНЦ РАН, Аnатиты, ivanova_la@inbox.ru

${ }^{3}$ Ресурсный иентр «Термогравиметрические и калориметрические методы исследования», Научный Парк, Санкт-Петербургский государственный университет, Санкт-Петербург, irina.zvereva@spbu.ru

Аннотация. Изучена трансформация вермикулитового субстрата в процессе длительной эксплуатации в гидропонной теплице. Изменение свойств вермикулита исследовано методами рентгенофазового и синхронного термического анализа с привлечением данных о гидрофизических свойствах и химическом составе. Полученные результаты показали, что длительное взаимодействие с водными растворами исходного вермикулитового субстрата, содержащего примесь флогопита, приводит к упорядочиванию чередования флогопитовых и вермикулитовых слоев и образованию смешаннослойной минеральной фазы. Положение и интенсивности низкотемпературных пиков на кривых нагревания исходного и отработанного вермикулита практически совпадают, что свидетельствует об отсутствии ионного обмена магния на другие катионы. Характерной особенностью отработанного вермикулита является появление в газовой фазе продуктов разложения органического вещества, содержащего серу, азот и углерод. Отработанный вермикулит удовлетворяет нормативным требованиям по содержанию тяжелых металлов и может быть использован для улучшения структуры почвы.

Ключевые слова: гидропонные технологии, вермикулитовый субстрат, физико-химическая трансформация, утилизация отходов.

\section{Physico-chemical transformation of hydroponic vermiculite substrate in the process of long-term operation and environmental problems}

\author{
Kremenetskaya I.P. ${ }^{1}$, Ivanova L.A. ${ }^{2}$, Chislov M.V. ${ }^{3}$, Zvereva I.A. ${ }^{3}$, Vasilieva T.N. ${ }^{1}$ \\ ${ }^{\prime}$ I.V. Tananaev Institute of Chemistry and Technology of Rare Elements and MineralRaw Materials, Kola \\ Science Centre, Russian Academy of Sciences, Apatity, i.kremenetskaia@ksc.ru \\ ${ }^{2}$ N.A. Avrorin Polar-Alpine Botanical Garden-Institute, Kola Science Centre, Russian Academy of Sciences, \\ Apatity,ivanova_la@inbox.ru \\ ${ }^{3}$ Centre of Thermal Analysis and Calorimetry, Research Park of Saint Petersburg State University, Saint \\ Petersburg,irina.zvereva@spbu.ru
}

\begin{abstract}
The transformation of vermiculite substrate during long-term operation in a hydroponic greenhouse was studied. The change in the properties of vermiculite was studied by X-ray phase and synchronous thermal analysis using data on hydrophysical properties and chemical composition. The results showed that prolonged interaction with aqueous solutions of the original vermiculite substrate containing phlogopite admixture leads to the ordering of the alternation of phlogopite and vermiculite layers and the formation of a mixed-layer mineral phase. The position and intensities of the low-temperature peaks in the heating curves of the initial and spent vermiculite practically coincide, which indicates the absence of ion exchange of magnesium for other cations. A characteristic feature of spent vermiculite is the appearance in the gas phase of the decomposition products of organic matter containing sulfur, nitrogen, and carbon. Spent vermiculite meets the regulatory requirements for heavy metals and can be used to improve soil structure.
\end{abstract}

Key words: hydroponic technologies, vermiculite substrate, physicochemical transformation, waste disposal.

\section{Введение}

В современных условиях для успешного ведения промышленного растениеводства важен поиск и применение новых эффективных способов выращивания растений, которые бы гарантировали оптимальный рост растений, обеспечивали население питанием и не нарушали экологическое рав- 
новесие. Широкое распространение в растениеводстве получили гидропонные теплицы с использованием вспученного вермикулита. После термообработки вермикулит приобретает такие свойства, как стерильность, благоприятные механические, гидрофизические и физико-химические свойства (Иванова, 2006).

Однако деградация субстратов, изменение их водно-физических свойств, механическое, химическое и биогенное вырождение, накопление продуктов жизнедеятельности растений при длительной эксплуатации субстратов в гидропонике (Asaduzzaman, Asao, 2012) зачастую являются причиной неудовлетворительного роста и развития растений и обусловливают возникновение экологических проблем, связанных с образованием отходов в виде отработанных гидропонных субстратов (Talukder et al., 2019). Таким образом, важным аспектом успешного внедрения вермикулитопоники является разработка способов утилизации отходов (Gwynn-Jones et al., 2018), что предопределяет необходимость проведения исследований по изучению изменения свойств вермикулита после многолетней эксплуатации в качестве гидропонного субстрата для выращивания растений.

\section{Объект исследования}

Исследованы материалы на основе вермикулита Ковдорского месторождения комплексных руд (г. Ковдор, Мурманская обл.). Размер частиц исходного вермикулита 10-20 мм. Данный образец обозначен как VRn. C целью применения в гидропонной теплице исходный вермикулит был подвергнут обжигу в лабораторной электрической вращающейся печи, полученный материал обозначен как VE. Отработанный вермикулит (VH) эксплуатировался в качестве гидропонного субстрата в течение 15 лет. Для проведения исследований образец VH был очищен от растительных остатков, промыт и высушен при температуре $105^{\circ} \mathrm{C}$. Исследован также вермикулит, полученный после обжига отработанного гидропонного субстрата (образец VHe).

\section{Гидрофизические характеристики образцов верликулита}

Гидрофизические свойства образцов представлены в таблице 1. Насыпная плотность является одним из наиболее важных показателей качества термовермикулита (Нижегородов, 2014). Её увеличение почти в четыре раза для $\mathrm{VH}\left(0.40\right.$ г/ $\left.\mathrm{cm}^{3}\right)$ по сравнению с исходным значением $\left(\rho(\mathrm{VE})=0.11 \Gamma / \mathrm{cm}^{3}\right)$ отражает совокупность процессов механического разрушения и возможной структурной трансформации минеральных фаз. Следует отметить, что свойства VH могут быть частично восстановлены путем повторной термообработки. Отработанный вермикулит приобрел способность вспучиваться, т.е. увеличиваться в объеме при нагревании. Коэффициент вспучивания составляет для природного вермикулита величину 5.9, а для отработанного вермикулита данный показатель закономерно меньше (2.2).

Таблица 1. Гидрофизические характеристики образцов вермикулита.

Table 1. Vermiculite samples hydrophysical characteristics.

\begin{tabular}{|c|c|c|c|c|c|}
\hline Образец & $\begin{array}{c}\text { Насыпная плотность, } \\
\text { Гсм }^{3}\end{array}$ & $\begin{array}{c}\text { Коэффициент } \\
\text { вспучивания }\end{array}$ & ппп $_{1000}, \%$ & $\begin{array}{c}\text { Водопоглощение, } \\
\text { мас. \% }^{3}\end{array}$ & $\begin{array}{c}\text { Гигроскопичность, } \\
\text { мас. \% }\end{array}$ \\
\hline $\mathrm{VRn}$ & 0.65 & 5.9 & 17.4 & 13 & 1.5 \\
\hline $\mathrm{VE}$ & 0.11 & - & 8.3 & 209 & 6.0 \\
\hline $\mathrm{VH}$ & 0.40 & 2.2 & 12.4 & 93 & 5.6 \\
\hline $\mathrm{VHe}$ & 0.18 & - & 8.0 & 130 & 5.0 \\
\hline
\end{tabular}

Примечание: ппп ${ }_{1000}-$ потери при прокаливании при $1000^{\circ} \mathrm{C}$.

О превращениях вермикулита можно судить на основании совокупности данных о водопоглощении, гигроскопичности и потерях при прокаливании. Наиболее существенные изменения наблюдаются для водопоглощения. Данный показатель является важной характеристикой гидропонного субстрата, поскольку отражает способность материалов удерживать питательный раствор (Putra, Yuliando, 2015). В процессе многолетней эксплуатации водопоглощение уменьшилось в два раза, т.е. произошла существенная деградация термовермикулита как гидропонного субстрата. После по- 
вторной термообработки водопоглощение увеличилось, но осталось меньше по сравнению с VE.

Гигроскопическая влага (количество сорбированной воды) является недоступной для растений. Данный показатель не претерпел существенных изменений в процессе использования термовермикулита, что свидетельствует о сохранении структуры трехслойных талькоподобных пакетов (Хвостенков и др., 1967). Об этом же свидетельствует и то факт, что потери при прокаливании при $1000^{\circ} \mathrm{C}$ (ппп ${ }_{1000}$ ) образцов VE and VHе отличаются незначительно ( $8.3 \%$ для VE и $8.0 \%$ для VHe).

\section{Фазовый и химический состав образцов вермикулита}

Согласно данным рентгенофазового анализа, исходный материал VE содержит помимо вермикулита заметную примесь флогопита. На дифрактограмме VE кроме рефлексов вермикулита (ISDD, 74-1732) присутствует серия отражений, характерных для флогопита (ISDD, 85-2274) (рис. 1). В отработанном в гидропонике образце VH сохранилась примесь флогопита, а вместо характерного для вермикулита отражения $\mathrm{d}=14.4 \AA$ появился дублет, который свидетельствует о том, что в процессе эксплуатации термовермикулита в теплице в качестве субстрата для гидропоники произошли изменения структуры вермикулита. Как правило, такое сочетание отражений (d=12.0 и $13.2 \AA)$ указывает, с одной стороны, на появление упорядоченности в переслаивании флогопит-вермикулитовых слоев (d=12.0-12.4 $\AA$ ) (Нырков, 2009) с другой - на весьма вероятный процесс ионного обмена, который может иметь место при использовании вермикулита для гидропоники в насыщенной среде питательного раствора. Об этом говорит появление нетипичного для чисто магниевого вермикулита отражения $\mathrm{d}=13.7 \AA$ (Тарасевич, 1988).

В работе (Kalinowski, Schweda, 2007) экспериментально моделировали процесс выветривания вермикулита с примесью флогопита при взаимодействии с растворами $\mathrm{HCl}$ при $\mathrm{pH} 2-5$. В условиях, приближенным к условиям закисления природных вод, исследованы закономерности превращения смеси исходных минералов в однородную фазу с регулярным переслаиванием слоев, которая характеризуется межплоскостным расстоянием $12.0 \AA$. В той же работе показано, что в результате взаимодействия вермикулита с раствором $\mathrm{HCl}$ при $\mathrm{pH}>3$ происходит инконгруэнтное растворение вермикулита с образованием фазы, обогащенной по алюминию. Алюминий мигрирует из тетраэдрического слоя в октаэдрический, что приводит к образованию новой фазы с межплоскостным расстоянием $13.92 \AA ̊$. Описание аналогичной фазы в геологических образцах вермикулита приведено в работе (Harraz, Hamdy, 2010).

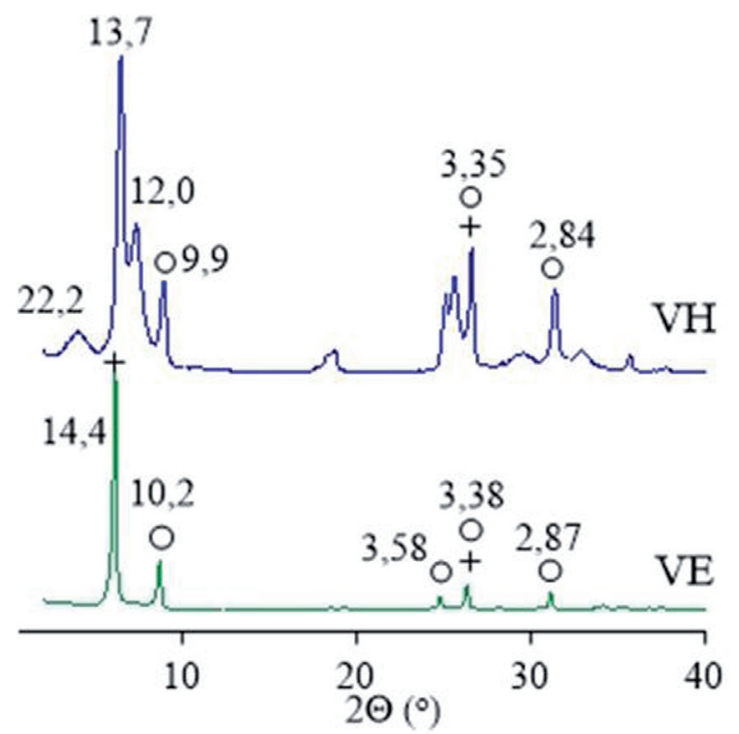

Рис. 1. Дифрактограммы образцов вермикулита VE и VH (+ вермикулит, о флогопит).

Fig. 1. X-ray diffraction patterns of VE and $\mathrm{VH}$ vermiculite samples (+ vermiculite, o phlogopite).
Для уточнения данных РФА исследовано поведение образцов VE и VН при нагревании (рис. 2). Соотношение интенсивностей низкотемпературных эффектов удаления воды, а именно слабое проявление второго эффекта, который обусловлен удалением воды из гидратной оболочки межслоевых ионов магния, подтверждает наличие значительной примеси флогопита в исходном образце (Harraz, Hamdy, 2010).

Положение и интенсивности низкотемпературных пиков на кривых нагревания VE and VH практически совпадают, что свидетельствует об отсутствии ионного обмена магния на другие катионы. В то же время, уменьшение потери массы в интервале температур $100-150$ и $150-220^{\circ} \mathrm{C}$ для VH по сравнению c VE говорит об изменении состава октаэдрического слоя. Результаты ДСК в области высоких температур (более $800^{\circ} \mathrm{C}$ ) отличаются для отработанного вермикулита по сравнению с исходным появлением эндоэффекта и сни- 


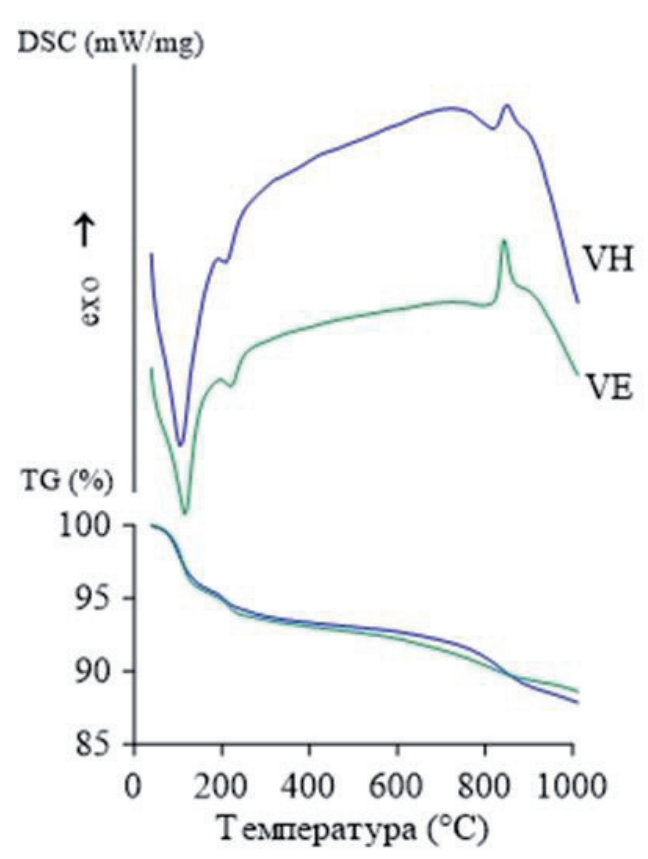

Рис. 2. Результаты термического анализа образцов VЕ иVH.

Fig. 2. The results of thermal analysis of samples $\mathrm{VE}$ and $\mathrm{VH}$.

жением интенсивности экзоэффекта, который связан с разрушением кристаллической структуры.

Наиболее вероятной причиной появления эндоэффекта является процесс разложения органического вещества, которое накапливается в процессе эксплуатации вермикулитового гидропонного субстрата. Об увеличении количества фазы, способной к разложению с образованием газообразных веществ, свидетельствуют данные о потерях массы и о составе газовой фазы. Потери массы в интервале температур 800-900 ${ }^{\circ} \mathrm{C}$ для образца ЛА-3 составляют $2 \%$ от массы образца, что в два раза больше по сравнению с данными для исходного вермикулита. В исходном вермикулите высокотемпературные потери массы связаны преимущественно с удалением гидроксильной воды, т.е. с разрушением структуры минерала. Характерной особенностью отработанного вермикулита является появление в газовой фазе, помимо воды, продуктов разложения органического вещества, содержащих серу и азот, а также увеличение по сравнению с исходным вермикулитом количества $\mathrm{CO}$ и $\mathrm{CO}_{2}$.

Таким образом, в процессе эксплуатации вспученного вермикулита в теплице происходят незначительные структурные изменения гидропонного субстрата и накопление в нем органического вещества. Результаты химического анализа отработанного вермикулита показали, что существенного изменения химического состава в процессе эксплуатации не происходит. Естественный химический состав и структурированность отработавшего в гидропонике вермикулита дают возможность дальнейшего его использования в качестве разрыхлителя почвы, улучшающего ее водный и воздушный режимы.

\section{Заключение}

Результаты настоящего исследования показали, что в процессе многолетней эксплуатации термовермикулита в гидропонной теплице происходит как механическое разрушение, так и изменение его кристаллической структуры. Особенностью исследованного термовермикулита является наличие в нем флогопита. В результате длительного воздействия раствора солей и органических кислот происходит образование новой фазы с регулярным чередованием вермикулитовых и флогопитовых слоев. Кроме того, наблюдается миграция алюминия из тетраэдрического слоя в октаэдрический, что также приводит к образованию новой фазы.

В отмытом от органических остатков отработанном вермикулите обнаружено наличие органического вещества, что свидетельствует об образовании органоминеральных комплексов на поверхности вермикулита. Данное свойство отработанного вермикулита является полезным при его использовании в качестве компонента почвы. Вермикулитовый субстрат, не пригодный для дальнейшего использования в защищенном грунте, но обладающий комплексом благоприятных физикохимических и биологических свойств, может быть использован для улучшения структуры почвы. Полевой эксперимент показал, что отработанный вермикулит оказывает положительное воздействие на рост и развитие картофеля.

Таким образом, показано, что вермикулитопоника позволяет возвратить в природную среду ранее изъятый ее фрагмент (минерал вермикулит) в нетоксичном состоянии. Это дает основание считать гидропонную технологию с использованием вермикулита безотходной и экологически безопасной. 
Термический анализ выполнен в Ресурсном центре «Термогравиметрические и калориметрические методы исследования» Научного Парка СПбГУ.

\section{Литература}

1. Иванова Л.А., Котельников В.В., Быкова А.Е. Физико-химическая трансформация минерала вермикулита в субстрат для выращивания растений // Вестник МГТУ. 2006. № 9(5). С. 883-889.

2. Нижегородов А.И. Исследование процессов теплоусвоения вермикулита и переноса теплового излучения в электрических модульно-спусковых печах для обжига вермикулитовых концентратов // Огнеупоры и техническая керамика. 2014. № 11-12. С. 40-47.

3. Нырков А.А. Кристаллохимическая классификация и номенклатура гидрослюд // Минералогический сборник. 2009. № 59. Вып. 2. С. 170-176.

4. Тарасевич Ю.И. Строение и химия поверхности слоистых силикатов. Киев. Изд-во: Наукова думка. 1988. $248 \mathrm{c}$.

5. Хвостенков С.И., Туркин А.Ф., Тимошенко О.М. Дегидратация и регидратация вермикулита // Геология, свойства и применение вермикулита. Л. Изд-во: Наука. 1967. С. 41-54.

6. Asaduzzaman Md., Asao T. Autotoxicity in beans and their allelochemicals. // Scientia Horticulturae. 2012. V. 134. P. 26-31.

7. Gwynn-Jones D. et al. Can the optimisation of pop-up agriculture in remote communities help feed the world? // Global Food Security. 2018. V. 18. P. 35-43.

8. Harraz H.Z., Hamdy M.M. Interstratified vermiculite-mica in the gneiss-metapelite-serpentinite rocks at Hafafit area, Southern Eastern Desert, Egypt: From metasomatism to weathering // Joumal of African Earth Sciences. 2010. V. 58. P. 305-320.

9. Kalinowski B.E., Schweda P. Rates and nonstoichiometry of vermiculite dissolution at $22^{\circ} \mathrm{C} / /$ Geoderma. 2007. V. 142. P. 197-209.

10. Putra P.A., Yuliando H. Soilless Culture System to Support Water Use Efficiency and Product Quality: A Review // Agriculture and Agricultural Science Procedia. 2015. V. 20153. P. 283-288.

11. Talukder Md.R. Asaduzzaman Md., Tanaka H., Asao T. Electro-degradation of culture solution improves growth, yield and quality of strawberry plants grown in closed hydroponics. // Scientia Horticulturae. 2019. V. 243. P. 243-251. 